
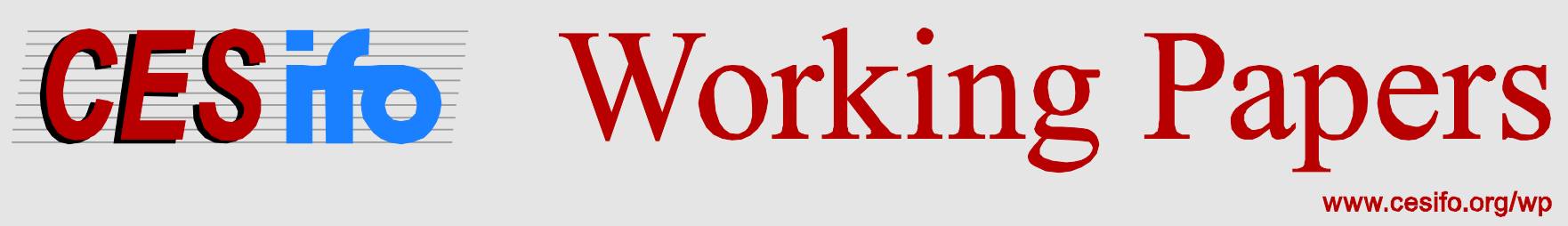

\title{
A Lipsetian Theory of Democratization: Development, Education, Inequality, and Resources
}

\author{
Raouf Boucekkine \\ Paolo G. Piacquadio \\ Fabien Prieur
}

CESIFO WORKING PAPER NO. 6283

CATEgory 2: Public CHOICE

DECEMBER 2016

An electronic version of the paper may be downloaded

- from the SSRN website: Www.SSRN.com

- from the RePEc website: Www.RePEc.org

- from the CESifo website: www.CESifo-group.org/wp 


\title{
A Lipsetian Theory of Democratization: Development, Education, Inequality, and Resources
}

\begin{abstract}
The paper reexamines Lipset's theory of democratization, by distinguishing the role of (economic) development from that of education, inequality, and (natural) resources. We highlight two contrasting effects of education and human capital accumulation. On the one side, education prompts economic growth and enriches the budget of the autocratic elite. On the other side, education increases the "awareness" of citizens - capturing their reluctance to accept a dictatorship and their labor-market aspirations - and forces the elite to expand redistribution. Along the lines of this trade-off, our theory provides a Lipsetian explanation of the positive relationship between economic development, education, and democratization, and of the negative relationship between inequality and democratization. Furthermore, we obtain new insights on the resources-curse hypothesis and on the design of effective aid to education.
\end{abstract}

JEL-Codes: D720, I250, O110, O430.

Keywords: democratization, human capital, Lipset's theory, resource curse.

\author{
Raouf Boucekkine \\ Aix-Marseille University \\ School of Economics \\ Marseille / France \\ raouf.boucekkine@univ-amu.fr
}

Paolo G. Piacquadio

Department of Economics

University of Oslo

Oslo / Norway

p.g.piacquadio@econ.uio.no

Fabien Prieur

Toulouse School of Economics

University of Toulouse Capitole (INRA)

Toulouse / France

prieur@supagro.inra.fr

December, 2016 


\section{Introduction}

Whether economic development is a prerequisite of democratization or one of its side products is an unsettled question in social sciences. Perhaps the most influential contemporaneous work on this theme is due to Lipset $(1959,1960)$. Lipset suggested that modernization causes democratization and provided a first empirical relationship between indexes of development and democratic regimes. His view is that democracy requires a significant civic engagement, a political culture of negotiation, and the recognition of the need for compromises. As these values are typical of developed societies, characterized by high education, urbanization, individual mobility, and low inequality, he concludes that economic development is conducive to democratization.

In recent years, this view has been challenged. The relationship between economic development and democratization may be driven by the stability of rich democracies, as opposed to poorer ones (Przeworski et al., 2000). Moreover, the colonial origins of institutions is suggestive of the fact that institutions may be the ultimate cause of development, and not the reverse (see Acemoglu et al., 2001, and Rodrik et al., 2004). Yet, human capital and culture may be considered an even more fundamental source of growth than institutions (Barro, 1999; Glaeser et al., 2004; and Gorodnichenko and Roland, 2015). ${ }^{1}$ As of today, it is fair to say that the econometric debate is still undecided (see also Boix and Stokes, 2003; Acemoglu et al., 2005; Epstein et al., 2006; Castello-Climent, 2008; Papaioannou and Siourounis, 2008, Che et al., 2013).

This richness of possible stories is an evidence of the complexity of the issue. At the same time, it calls for a reexamination of Lipset's modernization theory by disentangling "economic development" into its components - i.e. wealth, education, culture, inequality, natural

\footnotetext{
${ }^{1}$ They argue that the typical institutional indicators considered by Acemoglu et al. (2001) rather capture volatile outcomes than durable norms (as should proxys for institutions do). For example, certain popular measures of constraints on governments are shown to be twice as volatile (in terms of average within country deviations) as Barro's measure of years of schooling. Also the different experiences of North and South Korea, which have been part of the same country until the early 1950s, seem to require other explanation than what Acemoglu and coauthors provide (see details of the argument in Glaeser et al., 2004).
} 
resources - and by analyzing their interaction and implications for democratization. Two decades ago, Barro (1996) wrote that: "given the strength of the Lipset/Aristotle hypothesis as an empirical regularity, it is surprising that convincing theoretical models of the relation do not exist." In this paper, we take up this challenge in light of the more recent empirical findings.

Our model of democratization allows us to explore simultaneously three essential features of Lipset's theory: the link between education and democracy; the link between economic development and democracy; and the link between inequality and democracy. In this sense, our theory is a more comprehensive exploration of the implications of the Lipsetian thought. Moreover, a major distinctive feature of our model is the focus on the role of resource-dependence of the economy under scrutiny, which fits a largely significant number of autocratic regimes in the world, notably among the Arab countries. We assume that the economic power of the elite originates from the full control of a windfall of resources (natural resources or other). This allows us to address whether resource abundance undermines the democratization process in our framework, as advocated by the proponents of the institutional resource curse view (see for example, Ross 2001, and Tsui, 2011). Moreover, we can also investigate the role of natural resources for education policies (see Gylfason, 2001) and, then, jointly on democratization.

Concretely, we study the paradigmatic case of autocratic elite with full political and economic power. In line with the recent literature on democratization games (see Acemoglu and Robinson, 2006), the elite anticipate the existence and extent of revolutionary threats. They can act to avoid revolutions in two ways. They can either introduce appropriate redistribution and wage-setting policies to placate the incentives to revolt of the citizens. Or, they can start the democratization process and dismiss their power. ${ }^{2}$ The key decision is whether the

\footnotetext{
${ }^{2}$ Contrary to the Acemoglu-Robinson literature, we abstract from the case where institutional changes are forced by violent popular uprises (in contrast to Acemoglu and Robinson, 2006, and, more recently, to Guttman and Reuveny, 2014, and Boucekkine et al., 2016). In our model, the elite design the redistribution policy in order to avert revolutions and they can always do it in our framework. This choice suggests that our theory is more likely to capture long-lasting transitions, rather than temporary regime changes.
} 
elite would go for a development path leading to democratization or would rather decide to keep the power. That the elite anticipates and reacts to the threat of revolution is consistent with the empirical evidence on (democratic) reforms in Great Britain, Western Europe, and sub-Saharan Africa (see Aidt and Frank, 2015, and references therein). However, by eliminating the possibility of unanticipated and violent revolutions - as well as the corresponding institutional changes - our setting is more likely to capture those institutional changes that lead to stable democracies (see Glaeser et al., 2007).

Citizens are hand-to-mouth workers: they are employed in the national industry and consume in each period their labor income and transfers. If their consumption - and thus life satisfaction - does not reach a specific threshold, workers would revolt. This threshold is determined by two components. The first captures: the subsistence level of consumption; cultural and social aspects capturing the willingness to revolt, such as the degree of individualism or collectivism of workers (see Gorodnichenko and Roland, 2015); and expected cost of revolts, i.e. those related to the military power of the autocracy. The second component is endogenous and depends on the level of human capital of the workers. The idea is that as citizens become more educated, they also become more aware of the political situation (see Zaller, 1992) and they tend to be more politically sophisticated (see Luskin, 1990, and Neuman, 1986). Moreover, as suggested by Campante and Chor (2012) to explain the Arab Spring events, they also have higher income expectations and require better working opportunities. ${ }^{3}$ Consequently, the education policy set by the elite has two opposite effects. On the one side, human capital is a production factor in the economy, so education enhances labor productivity and triggers economic growth. On the other side, human capital accumulation has the above-described "awareness" cost, making workers more demanding and possibly leading to the disruption of the incumbent elite. The latter effect has been already

\footnotetext{
${ }^{3}$ Education is certainly more multifaceted than what economists generally assume. As argued by Chomsky (1996), education can be paradoxically used to obtain "ignorance," with the aim of standardization and domination of populations. This view is supported empirically by Castello-Climent and Mukhopadhyay (2013). For the sake of tractability, we abstract from non-monotonic effects of education on peoples desire for freedom.
} 
put forward by several authors to explain the lack of support for mass education and/or its late set-up in England (see Galor and Moav, 2006, on the 1870 Forster act), in India (see Pal and Ghosh, 2012, on the role of the landed elite against investment in basic education), or in Southern US (see Ager, 2013, on the planters elite's lack of support for mass schooling in the nineteenth century).

Our theory predicts two possible scenarios. In some countries, the elite would decide to keep investment in education low, rely massively on resource export, and redistribute to citizens just enough to prevent a revolution. Surprisingly, in other countries, the elite might undertake a path leading to an institutional change in a finite time horizon. Despite their full political and economic power, the elite might opt for high investment in education, a progressive reduction of the dependence on resource export, increasing claims of citizens, a reduction of inequality, and, eventually, a voluntary power dismissal by the elite.

These predictions are broadly in line with Lipset's theory of institutional change, but also clarify the specific role of education, culture, inequality, and natural resources. The democratization path is triggered by the correct balance between economic returns to citizens' education and their increasing claims to consumption. In particular, a high level of human capital is both a prerequisite and a consequence of institutional change. It is a prerequisite as the elite would dismiss their power only if the economy becomes rich enough to guarantee sufficient economic returns. It is a consequence as the elite anticipates the costs and benefits of the democratization path and optimally decides to reach such human capital level at the cost of their political power. This provides a new explanation of the Lipsetian link between economic development, education, inequality, and democratization. The positive correlation between economic development and democratization obtains due to education being the engine of growth. The negative correlation between inequality and democratization follows from the citizens becoming more aware and demanding as their human capital increases. Our results are consistent with the central role of education in the post-soviet transitions: Papaioannou and Siourounis (2008) find that democratization is "more likely to emerge in 
affluent and especially educated societies," while education is also a key factor determining the intensity and the pace of democratic reforms. These also provide further support to the idea that dictators may, in some circumstances, adopt growth enhancing policies, as emphasized recently by Shen (2007), Cervellati and Sunde (2014), and De Luca et al. (2015).

The presence of resources enriches the model with a further dimension. Consistent with Lipset's theory, we show that higher resource wealth is (weakly) favorable for democratization. This seems in contrast with the empirical support for the resource curse hypothesis, claiming that resource wealth strengthens autocratic regimes (Ross 2001, and Tsui, 2011). Also in this case, however, the empirical results are not conclusive and several studies find no positive relationship between resource wealth and the stability of autocratic regimes (Alexeev and Conrad, 2009, and Haber and Menaldo, 2011). Our proposed mechanism-through the investment in education and the development of citizens' aspiration for democracy-can rationalize this contrasting evidence: resource wealth cannot alone trigger the democratization process. Even though a country is resource rich, the democratization path may be suboptimal and dominated by permanent dictatorship. This case emerges when, for example, the education sector is not very effective and/or when the elite expect significant punishment and confiscations following the regime change.

Despite the abundant and mixed empirical results, there are only few attempts to capture Lipset's theory in a theoretical framework. Bourguignon and Verdier (2000) introduce an endogenous political economy decision mechanism that depends on the education of citizens: the ruling oligarchs set the education policy anticipating their effects on the economic growth, on inequality, on the political participation of citizens, and on the structure of political power. They show that a high initial per capita income is associated with a larger likelihood of a country to be in a democracy and to a quicker transition; initial inequality has, instead, the opposite effects. On a similar line, Glaeser et al. (2007) convey the idea that education raises the benefits of civic engagement pretty much as social capital, therefore leading to a larger social and political involvement. They further argue that education 
does not only favor the emergence of democracy, but also helps stabilizing it. More recently, Jung and Sunde (2014) have investigated the Lipset claim that democracy is more likely in countries with more equal distributions of resources. Three main differences characterize our contribution. First, by attributing full political and economic power to the elite, we further emphasize how powerful education policies can be for institutional change. Second, by disentangling the role of classic correlates of economic development-i.e. income, education, culture, inequality, natural resources - we provide a new set of predictions that can be used to reassess the empirical evidence. Third, by introducing natural resources, we bring together the literature on institutional change, the literature on education-driven endogenous growth, and the literature on the natural resource course.

The remainder of the paper is organized as follows. Section 2 presents the model of the economy. Sections 3 and 4 study all the possible solutions and then compare them to determine the optimal choices. Section 5 concludes. All the proofs are gathered in the appendix.

\section{The model}

Time is continuous, i.e. $t \in \mathbb{R}_{+}$; the time index is omitted where no confusion may arise.

Society consists of a ruling elite and workers. The elite have control of a constant windfall of (natural) resources $R>0 .{ }^{4}$ Resources have two alternative uses. A part of it is exported on the international primary good market and sold at the exogenous price $p^{x}>0$-let export quantity be $X$-and, for the remaining part, it is supplied internally to the manufacturing sector-let domestic supply be $Q \leq R-X$.

The manufacturing sector is perfectly competitive. Firms employ resources $Q$ and the human capital $H$ of workers to produce a homogeneous commodity $Y$. The production

\footnotetext{
${ }^{4}$ This is consistent with the fact that most governments of MENA countries (or Central and Eastern Euorpean transitional countries) operate large parts of the natural resource industries. While governments exercise control over these industries, this doesn't prevent them from privitizing these sectors, as for example in Egipt (during the last years of presidency of Hosni Mubarak) or in Russia and the post-Soviet republics.
} 
function is Cobb-Douglas, i.e. $Y \leq F(Q, H)=A Q^{\alpha} H^{1-\alpha}$ with $\alpha \in(0,1)$.

The resource rent of the elite then consists of the international and domestic sales of resources. The use of this rent is threefold: a part $C$ is allocated for the elite's consumption; another part $\Theta$ is transferred to (or from) the workers; the remaining part $E$ is invested in education. Formally, the elite's budget constraint is:

$$
p^{x} X+p Q \geq C+\Theta+E,
$$

where $p=\alpha \frac{Y}{Q}$ is the competitive price of resources.

Investment in the education sector increases human capital of the workers according to the following accumulation function:

$$
\dot{H}=h(E, H)=h E-\delta H
$$

where $h>0$ measures the effectiveness of the education investment and $\delta \geq 0$ is the depreciation rate of human capital.

The transfer and the education investment allow the elite to supervise the level of life satisfaction and resentment of the workers. Workers-normalized to unity-inelastically supply their human capital $H$ to the manufacturing sector and earn the equilibrium wage $w=(1-\alpha) \frac{Y}{H}$. Their income is completed by the transfer $\Theta$ and is entirely consumed in each period. Note that transfers can be negative. If workers' human capital is large, part of their wage income might be taxed away by the elite and allocated to either their consumption or education investment.

The workers' life satisfaction and resentment depend on their consumption. If their income is not large enough, workers might not be able to afford enough consumption and may decide to contest the power of the elite. More precisely, there is a threshold level of consumption that triggers a revolt. This threshold consists of two components. Following the long tradition of Francois Quesnay and Adam Smith, the first component interprets a subsistence level of 
consumption $s>0$ (for a recent application, see Galor and Weil, 2000). Subsistence need not be limited to nutrition, clothing, and housing needs. In fact, this can also include specific cultural and social aspects, such as individualism or collectivism (see Gorodnichenko and Roland, 2015) or expected cost of revolts, i.e. those related to the military power of the autocracy. ${ }^{5}$ The second component is new to this literature. It captures the idea that, as workers get more and more educated, they raise their life satisfaction requirements. With education, workers become more aware of the political situation in the country and have higher claims for democracy (see Zaller, 1992), they become more politically sophisticated (see Luskin, 1990, and Neuman, 1986), and they require better working opportunities (see Campante and Chor, 2012). This "political awareness" component thus depends on the workers' level of human capital. For simplicity, it is a linear function of human capital with slope $\phi>0$, referred to as the political awareness parameter. Then, workers decision to revolt is summarized as follows:

$$
\begin{cases}\text { revolt } & \text { if } w H+\Theta<s+\phi H \\ \text { no revolt } & \text { otherwise }\end{cases}
$$

To focus on the causes of democratization, we formalize the implications of a revolt in a stylized fashion. If workers decide to revolt, the elite loose (at least part of) their political power and a more democratic regime emerges. Yet, while their political power might be (significantly) reduced, the resource ownership (or some part of it) ensures that their economic interests extend over the democratic regime. ${ }^{6}$ We thus capture these economic interests of the elite by a sharing rule. The sharing rule describes which share of the economic wealth goes to the elite at the time of regime switch. In particular, since wealth is an increasing

\footnotetext{
${ }^{5}$ The results are unchanged whether the elite uses part of the transfer $\Theta$ to setting optimally their military power.

${ }^{6}$ More realistically, the political power might be held by a government that represents, and is infulenced by, the elite. In this case, the elite might not have a specific interest in enduring indefinetely the autocratic regime. We leave to future research the more complex interactions between the elite, the government, and the military power. While these interactions may be responsible for different types of coups, revolts, and institutional changes, we believe our model unveils important aspects of the forces leading to democratization.
} 
function of human capital, we assume that the benefit for the elite is a linear function of the amount of human capital available. An alternative explanation is that, as argued by Lipset, human capital is tightly connected with negotiation and absence of violence; thus, the elite expect democratization in an economy with highly educated workers to be characterized by less political violence and lower economic expropriation.

Let $T \in \mathbb{R}_{+} \bigcup\{\infty\}$ be the time at which the workers revolt and the autocratic regime comes to an end (permanent dictatorship holds when $T=\infty$ ). The wealth accrued to the elite at the time of regime switch is $\pi H_{T}$, where $\pi>0$ defines the sharing rule. A key aspect of our model is the capacity of the elite to fully internalize workers' incentives to revolt. This capacity manifests itself in the additional — no revolt—constraint (3) faced by the elite, who will ultimately be the ones to decide whether or not to instigate the democratization process. Thus, democratization time $T$ is a control variable in the hands of the elite.

The intertemporal well-being of the elite is given by:

$$
U^{e}=\int_{0}^{T} e^{-\rho t} u(C) d t+e^{-\rho T} \pi H_{T}
$$

where the instantaneous utility function is $u(C) \equiv \frac{(C)^{1-\gamma}}{1-\gamma}$ with $\gamma \in(0,1)$ and $\rho>0$ is the discount rate. ${ }^{7}$

Before moving to the analysis, we further discuss three aspects of our model.

Remark 1 . The elite are particularly powerful. They are able to control the consumption/income of workers, and thus their willingness to revolt, in three different ways: (i) directly, by setting the transfer $\Theta$; (ii) indirectly, by deciding how many resources to supply to the national industry $Q$; and (iii) dynamically, by investing more or less in education $E$ and thus setting their level of human capital. Furthermore, they control the political transition process and choose the timing $T$ (possibly infinite) for the institutional change. While

\footnotetext{
${ }^{7}$ The assumption that the elasticity of consumption be positive ensures that the utility is positive for any value of consumption. This is needed for the continuation payoff at the time of institutional change, i.e. $\pi H_{T} \geq 0$, to be intrapersonal comparable. When instead $\gamma>1$, utility levels are strictly negative and an immediate institutional change (independently of the human capital level) is always optimal.
} 
unrealistic, our results are strengthened by this assumption (and by the lack of uncertainty): despite the elite's exceptional power, we show that the elite might decide to lead the country to democratization.

Remark 2. The resource windfall is sufficiently large. This assumption ensures that the elite can sustain the dictatorial regime when human capital is zero and makes the problem interesting.

A 1. $p^{x} R>s$ : The value of resources is larger than the subsistence consumption of the workers and gives the elite some freedom in how to allocate such wealth.

Remark 3. Detailed models of the post-autocratic regime do not change qualitatively our results. There is an alternative to imposing exogenously the "scrap value" $\pi H_{T}$ in the elite's well-being function. This consists in: (i) modelling explicitly the features of the economy after the institutional change; (ii) solving the corresponding optimization problem; and (iii) adopting the obtained value function as the scrap value for the elite maximization problem. While interesting, this approach introduces further mathematical complexity without affecting qualitatively our results. ${ }^{8}$ Similarly, the introduction of uncertainty about the type of post-autocratic regime or about the success of a revolt or about a reversal to dictatorship can all be captured by $\pi$.

\section{Permanent dictatorship vs institutional change}

The elite seek to maximize utility (4), subject to the budget constraint (1), equilibrium prices $p$ and $w$, the dynamics of human capital (2), and the revolution decisions of workers (3). To do so, the elite sets optimally the use of resources $Q$, own consumption $C$, transfers

\footnotetext{
${ }^{8}$ For instance, the second regime problem can be seen as an optimal growth problem with heterogeneous population: while all have equal democratic rights, elite and workers differ with respect to their wealth (ownership over resources) and human capital level. To solve such a problem, one has to specify a number of further variables: the relative size of the elite; the ownership structure; the human capital of the elite; etc... In our setting, these are all jointly captured by the constant $\pi$, i.e. the marginal effect of an additional unit of the workers' human capital on their scrap value.
} 
$\Theta$, and education $E$. Yet, substituting $\Theta$ from the non-revolt condition of workers (3), the optimization problem of the elite can be written as an optimal stopping problem, where $T$ is the time until which the constraint is met. Formally:

$$
\begin{array}{ll}
\max _{\{Q, E, T\}} & \int_{0}^{T} e^{-\rho t} u\left(p^{x}(R-Q)+A Q^{\alpha} H^{1-\alpha}-E-s-\phi H\right) d t+e^{-\rho T} \pi H(T) \\
\text { s.t. } & \dot{H}=h E-\delta H \\
& H(T)=H_{T} \text { is free } \\
& E \geq 0 \\
& H(0)=H_{0} \text { is given }
\end{array}
$$

Maximizing the criterion with respect to national resource supply $Q$, requires that national prices equalize international ones, i.e. $p=p^{x}$, and sets the optimal ratio between resources and human capital. ${ }^{9}$ Optimal investment in education equalizes the marginal benefit from education with the marginal cost of investing in education (in terms of foregone consumption). The optimal time $T<\infty$ for violating the no-revolt condition equalizes the elite's value of staying in the current dictatorial regime and the value of the salvage function. The optimality conditions are displayed in Appendix A.1.

Since the optimal stopping problem is non-convex, we proceed in two steps. First, we study the dynamics of: i) the system when education investments are strictly positive. Second, we study the cases of: ii) zero investments in education; and iii) alternating periods of positive and zero investments. As both i) and ii) may be solutions of our optimization problem (see Section 4), we also highlight how these potential solutions depend on the parameters of the model.

\footnotetext{
${ }^{9}$ The optimal resource supply of the elite to the national industry would determine a price wedge between international and internal resource prices in case of costly redistributive transfers. In this case, the elite would find it more profitable to redistribute income to workers by oversupplying resources and, indirectly, determining a wage increase. While this extension is potentially relevant for an empirical assessment, the results discussed are not affected.
} 


\subsection{Education-driven institutional change}

Define as follows the instantaneous return on human capital $\Omega$ and the instantaneous return on education investment $\chi$ :

$$
\begin{aligned}
& \Omega \equiv \frac{1-\alpha}{\alpha} p^{x}\left(\frac{\alpha A}{p^{x}}\right)^{\frac{1}{1-\alpha}}-\phi, \\
& \chi \equiv h \Omega-\delta .
\end{aligned}
$$

The instantaneous return on human capital is the difference between the (equilibrium) gross return of human capital and the feedback effect of human capital on workers' claims for democracy, given by the political awareness parameter $\phi$.

Any solution with strictly positive education $E>0$ satisfies the following necessary conditions for optimality (where the superscript 1 indicates the regime with positive education):

$$
\left\{\begin{array}{l}
C^{1}(t)=C_{0}^{1} e^{\frac{(\chi-\rho) t}{\gamma}} \\
H^{1}(t)=\left(H_{0}+\frac{h\left(p^{x} R-s\right)}{\chi}-\frac{\gamma h C_{0}^{1}}{\rho-\chi(1-\gamma)}\right) e^{\chi t}+\frac{\gamma h C_{0}^{1}}{\rho-\chi(1-\gamma)} e^{\frac{(\chi-\rho) t}{\gamma}}-\frac{h\left(p^{x} R-s\right)}{\chi} \\
\lambda^{1}(t)=\frac{\left(C_{0}^{1}\right)^{-\gamma}}{h} e^{(\rho-\chi) t}
\end{array}\right.
$$

We establish the following result.

Proposition 1. (i) There is no solution combining permanent dictatorship and positive education.

(ii) There may be a solution combining institutional change and positive education.

(a) This solution is characterized by accumulation of human capital, institutional change in finite time $T=T\left(H_{0}, R, \pi\right)$, and a corresponding end-point stock of human capital:

$$
H_{T}=\frac{h}{\rho-\chi}\left(\frac{\gamma(h \pi)^{-\frac{1}{\gamma}}}{1-\gamma}+p^{x} R-s\right)>0
$$


(b) Necessary conditions for the existence of such solution for all $H_{0} \in\left[0, H_{T}\right]$ are:

$$
\left\{\begin{array}{l}
\rho>\chi \\
p^{x} R-s>(h \pi)^{-\frac{1}{\gamma}}
\end{array}\right.
$$

(c) Sufficient conditions for the existence of a unique solution are (7) and $\chi>\underline{\chi}$, with $\underline{\chi} \in(0, \rho)$ the unique solution of:

$$
e^{\frac{\gamma \chi}{\rho-\chi}}=\frac{\rho\left[(1-\gamma)(\rho-\chi(1-\gamma))+\gamma^{2} \chi\right]}{(1-\gamma)(\rho-\chi)^{2}}
$$

This result gives a first insight into the predictions of our model concerning the Lipsetian links between human capital, education, and democratization. The proposition establishes the incompatibility between permanent dictatorship and education (i). From the perspective of the elite, human capital has two implications: one the one hand, it increases the consumption aspiration and wages of the workers; on the other hand, it increases the return of the elite at the time of democratization. Permanent dictatorship excludes the second implication. As for the first one, since transferring $\Theta$ to the workers is free, the elite finds it more effective to export all resources, bring the workers' human capital to zero, and meet their "no-revolt constraint" with transfers $\Theta$. When transfers are costly, some positive level of human capital may be consistent with permanent dictatorship.

For the solution with education-driven institutional change, $\rho>\chi$ sets an upper bound on the instantaneous returns to human capital. This is a necessary condition for existence. Under the opposite condition $\chi \geq \rho$, autocracy is too growth-friendly. The elite can invest in education and, due to the high returns, this stimulates growth of output (and citizens' consumption) while being compatible with the respect of the no-revolution constraint, which is in fact never binding. However, the solution with permanent dictatorship and positive education is not relevant because it would either violate the resource constraint, or imply resource imports to become infinite (with $X$ tending to $-\infty$ ). The second necessary existence 
condition in (7) states that resource windfalls net of the intrinsic subsistence consumption level should be larger than the level of consumption the elite just enjoy at the date dictatorship ceases, $C^{1}(T)$. Finally, a sufficient condition for existence requires that the returns to human capital be higher than a threshold $\underline{\chi}$, defined by (8). High enough returns to human capital logically guarantee that it is worthwhile for the elite to engage in the path of education and sustained capital accumulation.

Under $\rho>\chi$, the time path of consumption is decreasing whereas the stock of human capital is increasing. The intuition runs as follows. For the elite to find it optimal to democratize they should be able to accumulate a sufficient amount of human capital, which will directly affect the wealth they will hold in the post-dictatorship regime, and will also guarantee that they can enjoy their wealth in a peaceful environment. Thus investment in human capital should be favored over consumption. Moreover, by investing significantly in human capital, the elite foster the development of citizens' claims for a freer system through the increasing awareness mechanism. In order to delay the political regime change the elite have no other option but to transfer more and more resources to the citizens, even if this comes at the expense of their own consumption.

Note that under the conditions of Proposition 1, solutions that combine positive education and a revolution in finite time exist for any $H_{0} \leq H_{T}$. In other words, the stated conditions guarantee the existence of a solution with education-driven institutional change independently of the initial endowment in human capital. This is a reasonable feature of our model: it would otherwise be difficult to explain why some countries are doomed to dictatorial regimes exclusively based on their initial stock of human capital and would also raise the issue of identifying this initial period (of the development process). Importantly, this doesn't mean that the initial stock of human capital is irrelevant to our analysis. As far as the optimality analysis is concerned, this variable will be crucial to determine which one of the optimality candidates yields the optimum.

In addition, it is worth emphasizing some other interesting features of the first optimality 
candidates. They are summarized in the next two corollaries.

Corollary 1. The solution with education-driven institutional change is possible only if, ceteris paribus,

(i) Resource wealth, $p^{x} R$, is large enough.

(ii) Elite's incentives to democratize, that are provided by the share of wealth accruing to the elite after they give up power, $\pi$, are important enough.

(iii) The effectiveness of the education, $h$, needs to be important enough too. But, in contrast to resource wealth and the sharing rule, it should not take an excessive value since the instantaneous returns to education, $\chi$, cannot be too high.

These properties are in line with Lipset's theory in two essential aspects: the link between democratization and education; and the link between resources (or income) and democratization. ${ }^{10}$ First of all, the model predicts that a large amount of resources (or of their export price) is a precondition for the emergence of a non-dictatorial regime through human capital accumulation. However, the resource wealth of a country (measured by $p^{x} R$ ) is not the unique relevant determinant of democratization. Two further factors matter: a sufficient return to investment in education, $h$, and a sufficient reward for the elite at the time of institutional change, $\pi$. Democratization may not occur under large resource revenues because one of the two latter parameters is too small (leading to violating conditions (15)). Importantly, the interaction between the resource wealth and these factors is likely to be responsible for the mixed support for the natural resource curse hypothesis (see the debate opposing proponents of this hypothesis, Ross, 2001, and Tsui, 2011, and detractors, Alexeev and Conrad, 2009, and Haber and Menaldo, 2011) and is in line with the empirical studies pointing at the mismanagement of education in several oil-exporting countries (see Gylfason, 2001). Finally, notice that the role of the return to education is tricky: it should be high enough ceteris

\footnotetext{
${ }^{10}$ Note that they are a direct consequence of the second necessary condition in (7). Also note that the parameters $R$ and $\pi$ do not show up in the sufficient condition $\chi>\chi$ since they don't enter into the expressions of $\Omega$. In contrast, the parameters $h$ and $p^{x}$ enter this condition through $\Omega$.
} 
paribus for democratization via education to arise but it should not be too high as the induced wealth in the hands of the elite in such a case could be sufficient to compensate for the larger awareness of the workers. In this case, a developing dictatorship could be sustained, although no equilibrium paths exist (see the interpretation of $(7)$ ).

Next, we highlight how the time-to-democratization is affected by the parameters of the model (see the comparative statics exercise at the end of Appendix A.2).

Corollary 2. The optimal time for institutional change, $T=T\left(H_{0}, R, \pi\right)$, is decreasing in both the initial endowment in human capital, $H_{0}$, the resource windfall, $R$, and the sharing rule parameter, $\pi$.

The first two features strengthen the correlation between wealth and democratization discussed before. The larger is the initial stock of human capital (another possible measure of human wealth) or the windfall of resources, the quicker are the elite in driving the country into an institutional change. While the larger windfall is also associated to a larger level of human capital at the time of institutional change, such an effect is absent for the initial human capital level. Finally, the optimal time-to-democratization is decreasing in $\pi$. The elite compensate a less favorable sharing rule by increasing the human capital of the country at the institutional change, $H_{T}$. This requires a longer period of investment in education.

To end up this discussion, it is important to measure the elite's payoff associated with the solution with education-driven institutional change. Let such optimality candidate be referred to as regime 1 ; then the present value (for the elite) of following this regime is given by (hereafter, the optimal time for institutional change is expressed in terms of $H_{0}$ only):

$$
V^{1}\left(H_{0}\right)=e^{-\rho T\left(H_{0}\right)}\left(\frac{\gamma(h \pi)^{-\frac{(1-\gamma)}{\gamma}}}{(1-\gamma)(\rho-\chi(1-\gamma))}\left(e^{\frac{\left(\rho-\chi(1-\gamma) T\left(H_{0}\right)\right.}{\gamma}}-1\right)+\pi H_{T}\right)
$$

The typical dynamics corresponding to this first possible solution is depicted in Figure 1.

In the next section the other optimality candidates are briefly reviewed. 


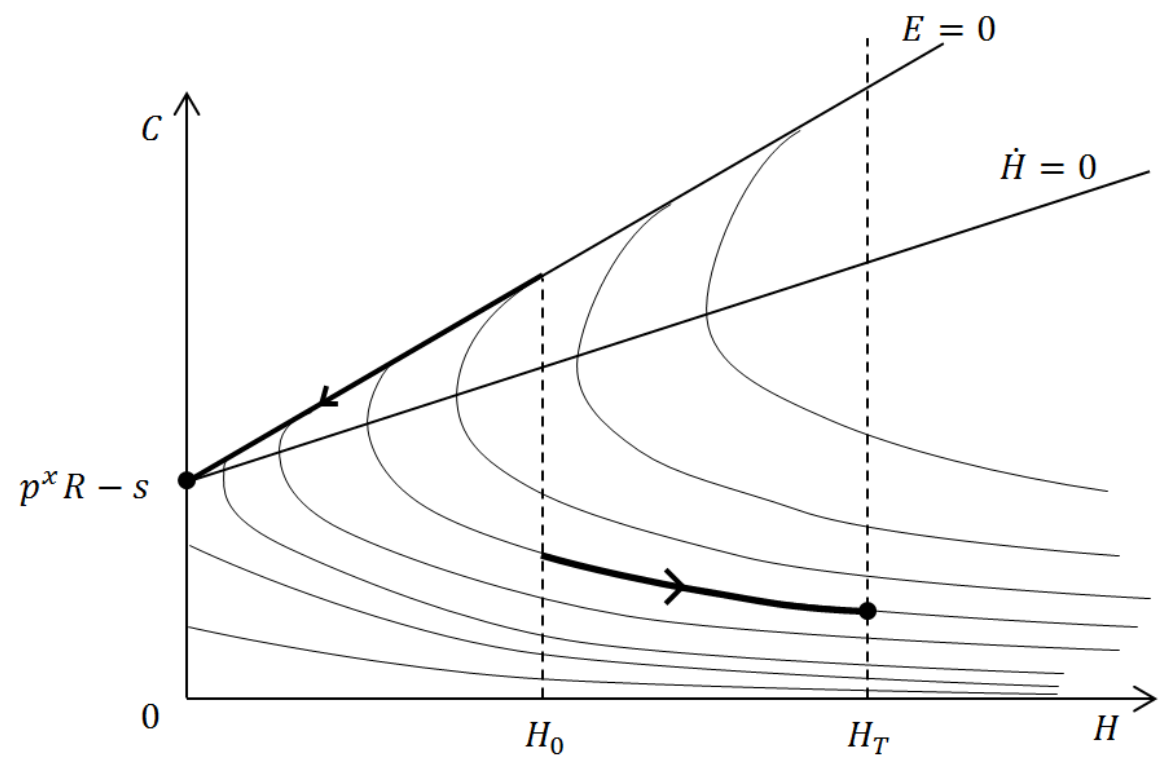

Figure 1: Phase diagram.

\section{$3.2 \quad$ No-education and permanent dictatorship}

The general solution corresponding to no investments in education, i.e. $E=0$, is given by (the superscript 2 refers to the regime with no education):

$$
\left\{\begin{array}{l}
C^{2}(t)=p^{x} R-s+\Omega H^{2}(t) \\
H^{2}(t)=H e^{-\delta t} \\
\lambda^{2}(t)=e^{(\rho+\delta) t}\left(L-\int \Omega C^{2}(u)^{-\gamma} e^{-(\rho+\delta) u} d u\right)
\end{array}\right.
$$

with $H$ and $L$ constants to be determined. We establish the following result:

Proposition 2. (i) There always exists a solution combining permanent dictatorship with no investment in education.

(ii) There may be solutions alternating periods of investment in education with periods of no investment, but these never provide a candidate for optimality.

The solution with permanent dictatorship and no education is characterized by a decreasing flow of consumption and a decreasing stock of human capital. Consumption asymptotically converges toward $C^{2}(\infty)=p^{x} R-s$, while the stock of human capital vanishes. This 
is the path taken by the elite that considers investment in human capital too costly in terms of resources needed by educated workers and in terms of the risk of being overthrown. Solutions with no education exist for any level of the stock of human capital. The value function corresponding to the optimality candidate with no education is given by:

$$
V^{2}\left(H_{0}\right)=\int_{0}^{\infty} \frac{1}{1-\gamma}\left(p^{x} R-s+\Omega H_{0} e^{-\delta t}\right)^{1-\gamma} e^{-\rho t} d t
$$

Finally, solutions featuring a regime change from positive to zero education can be disregarded because these are always dominated by other solutions (see Appendix A.3).

At this stage of the analysis, we are left with two optimality candidates, which makes the options available to the elite very clear. Either they choose to rely on resource wealth and not to invest in education in order to keep the labor force uneducated and docile. But this requires sacrificing education-driven economic growth. Or, the elite engage in a policy of sustained investment in education, which promotes the accumulation of human capital at the cost of giving up political power in finite time because of the development of citizens' claims for democracy. As expected, variables like the returns to education (and human capital), the initial stock of human capital, the discount rate but also the share of wealth accruing to the elite after a revolution will play a central role in explaining what is the elite's best option.

Before determining the optimal choice of the elite, we compare regime 1 and 2 in terms of their implications for the link between inequality and institutional change.

\subsection{Implications for inequality}

So far, we have addressed the links income-institutional change and human capital-institutional change. In this respect, we have shown that the predictions of the model are consistent with Lipset's theory. It remains to study the link inequalities-institutional change.

As workers are a homogeneous mass of individuals, the only way to appraise inequalities in a direct and elementary way is by tracking the consumption of the elite vs. the consumption 
of workers. Although this is not completely in the spirit of Lipset's theory concerning this aspect (see Jung and Sunde, 2014, for a tighter connection), this exercise turns out to be worthwhile. Recall that the workers' income is entirely devoted to consumption. At any solution, we have $C_{W}^{i}(t)=s+\phi H^{i}(t)$ for $i=1,2$. Let $I^{i}(t) \equiv \frac{C_{W}^{i}(t)}{C^{i}(t)}$ be the index of inequalities at solution $i=1,2$. Then, we can establish the following result.

Proposition 3. At the solution with education-driven institutional change, inequalities continuously shrink. At the solution with permanent dictatorship and no investment in education, the opposite result holds if:

$$
R>\frac{(1-\alpha) s}{\phi \alpha}\left(\frac{\alpha A}{p^{x}}\right)^{\frac{1}{1-\alpha}}
$$

Along the transition process to non-dictatorship, inequalities decrease. It is as if in order to prepare the ground for a democratic regime, the elite have to progressively reduce the income (consumption) gap between the two groups until the institutional change. Intuitively, since the elite invest in human capital along this path, growth is stimulated. But the positive growth effect is dominated by the negative effect due to increasing awareness and the elite have no option but to sacrifice part of their consumption to satisfy the no-revolt constraint and delay the date of leaving office.

Moreover and not surprisingly, permanent dictatorship implies a widening of inequalities if resource windfalls are high, the awareness cost is large, the international resource price is high, and the level of subsistence consumption is low. Under these conditions, the dictator is able to fill the revolt constraint at lower cost. By not investing in human capital, citizens are maintained under control while the elite become richer and richer relative to the workers.

The next section investigates the optimality of the above-identified solutions.

\section{Optimality, poverty trap, and policy implications}

The optimality analysis boils down to a study of the relative performance of the solution with education-driven institutional change vs. the solution with permanent dictatorship and 
no-education. To conduct this analysis, we compare the present values associated with our optimality candidates. We summarize the results as follows:

Proposition 4. Let $H_{0} \in\left[0, H_{T}\right]$. The following cases can arise:

(i) The solution with permanent dictatorship and no-education is optimal for all $H_{0}$ iff $V^{2}\left(H_{T}\right)>V^{1}\left(H_{T}\right)$

(ii) The solution with education-driven institutional change is optimal for all $H_{0}$ iff $V^{1}(0)>$ $V^{2}(0)$

(iii) Otherwise, a human capital poverty trap arises. There exists $\bar{H} \in\left[0, H_{T}\right]$ such that the solution with education-driven institutional change is optimal iff $H_{0} \geq \bar{H}$.

Both the no-education regime with persistent dictatorship and the education regime with democratization can arise. Depending on the parameters, it might be possible that: (i) the first alternative is chosen independently of the initial stock of human capital; (ii) the second alternative is chosen independently of the initial stock of human capital; and (iii) the regime choice depends on the initial human capital stock, a low stock is associated to no-education investment and infinite horizon dictatorship while a large stock is associated to education investment and democratization in finite time.

This result sheds light on the relationship between education, development, and democratization. First, education is necessary for both development and democratization: it is the engine of economic growth; and, by increasing the workers awareness, it is also responsible for the institutional change. Second, education investments might be optimal for the ruling elite, despite it might lead to more democratic institutions, as their political power gets substituted by economic returns. Third, the existence of a poverty trap is particularly interesting for it teaches that development aid leading to "small" increases in human capital might not be sufficient for a regime switch and thus fails to have permanent effects on development and institutions of the recipient country. Indeed, our theory delivers much more in this respect, and we shall come back to this implication below. 
The next result further emphasizes the conditions under which the elite find the democratization path optimal.

Proposition 5. The solution with education-driven institutional change is optimal for all $H_{0} \in\left[0, H_{T}\right]$ if:

$$
p^{x} R-s>e^{\frac{\gamma}{1+\gamma}}(h \pi)^{-\frac{1}{\gamma}}
$$

This sufficient condition can easily be interpreted once one observes that it is a stronger version of the second necessary existence condition (7). It confirms the previous intuition about which factors are crucial for the decision of the elite to educate the population and drive the country out of autocracy. Indeed, Proposition 5 illustrates that institutional change initiated by the elite is a matter of having the right conditions. A large stock of resources might not trigger education policies and democratization if the education sector doesn't ensure sufficient economic returns to the elite. A permanent positive shock to international resource prices might give the elite the wealth needed to invest in education and human capital accumulation, but this opportunity will not be taken if the wealth prospects at the time of institutional change are not sufficiently compelling.

Last but not least, it is important to interpret the above results in light of education aid policies. Case iii) of Proposition 4 indicates that the model can deliver (optimal) poverty traps. Propositions 3 and 5-with the associated necessary and sufficient conditions (7) and (10) - teach us that a massive aid policy of education systems may temporarily increase human capital, i.e. by improving access to education and therefore raising the enrollment rates. Yet, this may not have a permanent economic and institutional effect. One reason is that education aid might be unable to improve sufficiently education systems, i.e. the parameter $h$ might not reach the level needed to escape the poverty trap. Another reason is that institutional conditions are not good enough (here for example, $\pi$ should be big enough). This is consistent with the view questioning the efficiency of large aid to the poorest countries (see Kraay and Raddatz, 2007, for example).

Thus, aid programs should target education efficiency at the same time as educational 
outcomes, especially in those economies where the resource wealth is limited. Our theory produces a clear hierarchy in this respect: if education efficiency (our parameter $h$ ) is above a certain threshold value for education, development and democratization will turn optimal ceteris paribus irrespective of the initial value of capital $\left(H_{0}\right)$ and even though the country is run by an autocratic regime (as one can infer from Proposition 5). This result suggests a clear-cut way to settle the traditional tradeoff between expanding school enrollments versus improving school quality faced by development agencies.

\section{Conclusions}

In this paper we reexamine Lipset's theory of democratization. We distinguish the role of economic development from that of education, natural resources, culture, and inequality. The key mechanism at play is the feedback effect of education policies on the awareness of workers, measuring their understanding of the political system, their political sophistication, and, more in general, their reluctance to accept a dictatorship. Human capital is complementary to natural resources; it makes the national industry more productive; and is the engine of economic growth. At the same time, human capital faces a political cost in terms of the larger services/transfers that workers require to be refrained from revolting.

The main result of the paper is to show that two possible regimes can emerge, depending on the relative magnitude of the education incentives, on the size of natural resources, and on the economic returns for the elite after the democratization. In some countries, the ruling elite may support a permanent dictatorship characterized by low education, low growth, high inequality, and low levels of worker's life conditions. In other countries, instead, the elite might opt for large investment in education and a rapid human capital accumulation, even though the high growth path, the improving life conditions, and the reduction of inequality inevitably lead to the end of dictatorship.

Our theory is consistent with Lipset's in the three essential dimensions: the positive 
link between human capital and institutional change, the positive link between income and institutional change and, in a more stylized fashion, the negative link between inequality and institutional change. It also gives new insights on the "resource curse" hypothesis. Our analysis explains the mixed empirical support for the resource curse. Resource wealth may promote the transition from autocratic regimes to democracies, but only if combined with other crucial ingredients, such as the quality of the education sector and of the institutional system.

An important policy implication can be drawn in terms of aid programs intended to promote development. Education support may trigger the accumulation of human capital, sustained growth, and, as a side-product, democratization. However, its effectiveness requires: i) that development programs be large enough; and ii) that these be directed to the improvement of the education system (i.e. quality of teaching and school infrastructure), rather than to the achievement of specific education achievements (i.e. a certain level of alphabetization).

\section{References}

[1] Acemoglu, D. \& S. Johnson \& J. Robinson, 2001. The Colonial Origins of Comparative Development: An Empirical Investigation, American Economic Review, vol. 91(5), pages 1369-1401.

[2] Acemoglu, D. \& S. Johnson \& J. Robinson \& P. Yared, 2005. From Education to Democracy?, American Economic Review, Papers and Proceedings, vol. 95(2), pages 44-49.

[3] Acemoglu, D. \& J. Robinson, 2006. Economic Origins of Dictatorship and Democracy, Cambridge University Press.

[4] Ager, P. P., 2013. The Persistence of de Facto Power: Elites and Economic Development in the US South, 1840-1960, EHESE Working Papers in Economic History $N^{o} 38$.

[5] Aidt, T.S., \& R. Franck, 2015. "Democratization under the threat of revolution: Evidence from the Great Reform Act of 1832." Econometrica, Vol. 83, pages 505-547.

[6] Alexeev, M. \& R. Conrad. 2009. The Elusive Curse of Oil. Review of Economics and Statistics, vol. 91(3), pages 586-598. 
[7] Amit, R. 1986. Petroleum reservoir exploitation: Switching from primary to secondary recovery. Operations Research, vol 34, pages 534-549.

[8] Barro, R., 1999. Determinants of Democracy, Journal of Political Economy, vol. 107, pages 158-183.

[9] Boix, C. and S. Stokes, 2003. Endogenous democratization, World Politics, vol. 55, pages 517549.

[10] Bourguignon, F. \& T. Verdier, 2000. Oligarchy, Democracy, Inequality and Growth, Journal of Development Economics, vol. 62, pages 285-313.

[11] Boucekkine, R. \& F. Prieur \& K. Puzon, 2016. On the Timing of Political Regime Changes in Resource-Dependent Economies, European Economic Review, vol. 85, pages 188-207.

[12] Campante, F. \& D. Chor, 2012. Why Was the Arab World Poised for Revolution? Schooling, Economic Opportunities, and the Arab Spring, Journal of Economic Perspectives, vol. 26(2), pages $167-88$.

[13] Castello-Climent, A. \& A. Mukhopadhyay, 2013. Mass education or a minority well educated elite in the process of growth: The case of India, Journal of Development Economics, vol. $105(\mathrm{C})$, pages 303-320.

[14] Castello-Climent, A. 2008. On the distribution of education and democracy, Journal of Development Economics, vol. 87(2), pages 179-190.

[15] Cervellati, M. \& Sunde, U., 2014, Civil Conflict, Democratization, and Growth: Violent Democratization as Critical Juncture, Scandinavian Journal of Economics, vol 116, pages 482-505.

[16] Che, Y. \& Y. Lu \& Z. Tao \& P. Wang, 2013, The Impact of Income on Democracy Revisited, Journal of Comparative Economics, vol 41, pages 159-169.

[17] Chomsky, N., 1996. Class Warfare: Interviews with David Barsamian. Common Courage Press Monroe.

[18] De Luca, G., Litina, A. \& P. Sekeris, 2015. Growth-friendly dictatorships, Journal of Comparative Economics, vol. 43, pages 98-111.

[19] Epstein, D. \& R. Bates, I. Goldstone, I. Dristensen, S. O'Halloran, 2006. Democratic transitions, American Journal of Political Science, vol. 50, pages 551-569.

[20] Galor, O. \& D. Weil, 2000. Population, technology, and growth: From Malthusian stagnation to the demographic transition and beyond, American Economic Review, vol. 90, 806-828. 
[21] Galor, O. \& O. Moav, 2006. Das Human Kapital: A Theory of the Demise of the Class Structure?, Review of Economic Studies, vol. 73, 85-117.

[22] Glaeser, E. \& R. La Porta \& F. Lopez-de-Silanes \& A. Shleifer, 2004. Do Institutions Cause Growth?, Journal of Economic Growth, vol. 9(3), pages 271-303.

[23] Glaeser, E. \& G. Ponzetto \& A. Shleifer, 2007. Why does democracy need education?, Journal of Economic Growth, vol. 12(2), pages 77-99.

[24] Gorodnichenko, Y. and G. Roland, 2015. Culture, institutions and democratization. NBER, No. w21117.

[25] Guttman, J.M. \& Reuveny, R., 2014, On revolt and endogenous economic policy in autocratic regimes, Public Choice, vol. 159, pages 27-52.

[26] Gylfason, T., 2001. Natural resources, education, and economic development, European Economic Review, vol. 45(4-6), pages 847-859.

[27] Haber, S. \& V. Menaldo. 2011. Do Natural Resources Fuel Authoritarism? A Reappraisal of the Resource Curse. American Political Science Review, vol. 105(1), pages 1-26.

[28] Jung, F. \& U. Sunde, 2014. Income, inequality, and the stability of democracy: Another look at the Lipset hypothesis, European Journal of Political Economy, vol. 35(C), pages 52-74.

[29] Kraay, R. \& Raddatz, C. , 2007. Poverty traps, Aid and Growth, Journal of Development Economics, 82, 315-347.

[30] Lipset, S., 1959. Some social requisites of democracy: economic development and political legitimacy. American Political Science Review, Vol. 53, pages 69-105.

[31] Lipset, S., 1960. Political Man: The Social Bases of Modern Politics. New York: Doubleday.

[32] Luskin, R., 1990. Explaining Political Sophistication, Political Behavior, vol. 12 (4), pages 331-361.

[33] Neumann, R., 1986. The Paradox of Mass Politics: Knowledge and Opinion in the American Electorate. Harvard University Press.

[34] Pal, S. \& Ghosh, S., 2012. Poverty, elite heterogeneity and the allocation of public spending: Panel evidence from the Indian state, The Review of Income and Wealth, 58, 51-78.

[35] Papaioannou, E. \& Siourounis, G., 2008. Economic and Social Factors Driving the Third Wave of Democratization, Journal of Comparative Economics, vol. 36, pages 365-387. 
[36] Przeworski, A. \& M. Alvarez \& J. Cheibub \& F. Limongi, 2000. Democracy and Development: Political Institutions and Well-being in the World. Cambridge: Cambridge University Press.

[37] Rodrik, D. \& A. Subramanian \& F. Trebbi, 2004. Institutions Rule: The Primacy of Institutions Over Geography and Integration in Economic Development, Journal of Economic Growth, vol. $9(2)$, pages 131-165.

[38] Ross, M. 2001. Does Oil Hinder Democracy? World Politics, vol. 53, pages 325-361.

[39] Shen, L. 2007. When will a dictator be good?, Economic Theory, vol. 31, pages 343-366.

[40] Tsui, K. 2011. More Oil, Less Democracy: Evidence from the Worldwide Crude Oil Discoveries. Economic Journal, vol. 121, pages 89-115.

[41] Zaller, J., 1992. The Nature and Origins of Mass Opinion. Cambridge: Cambridge university press.

\section{A Proofs}

\section{A.1 Optimality conditions}

Let $\lambda$ be the costate variable associated with human capital. Its equilibrium dynamics is:

$$
\dot{\lambda}=(\delta+\rho) \lambda-C^{-\gamma}\left((1-\alpha) A\left(\frac{Q}{H}\right)^{\alpha}-\phi\right)
$$

Maximizing the criterion with respect to national resource supply $Q$, requires that national prices equalize international ones, i.e. $p=p^{x}$, and sets the optimal ratio between resources and human capital as follows:

$$
\frac{Q}{H}=\left(\frac{\alpha A}{p^{x}}\right)^{\frac{1}{1-\alpha}}
$$

At the equilibrium, optimal investment in education is such that the marginal benefit from education equals the marginal cost of investing in education (in terms of foregone consumption). Let $\mu$ be the Lagrange multiplier associated with the positivity constraint on education, this yields the optimal consumption of the elite:

$$
C=(\lambda h+\mu)^{-\frac{1}{\gamma}}
$$

The slackness conditions on education investment $E$ require:

$$
\mu \geq 0 \quad \text { and } \mu E=0
$$


The optimal time $T<\infty$ for violating the no-revolt condition and inducing a regime change is such that the current value of the Lagrangian be equal to the value of the salvage function; i.e.:

$$
u(C(T))+\lambda[h E(T)-\delta H(T)]=\rho \pi H(T)
$$

Finally, the transversality condition requires that:

$$
\lambda(T)=\left.\frac{\partial S(H)}{\partial H}\right|_{H=H(T)}=\pi
$$

Convexity of the problem with respect to optimal education investment $E$ and internally supplied resources $Q$ guarantees that the corresponding second order conditions are always satisfied. The second order conditions for the optimal stopping problem are not necessarily met.

\section{A.2 Proof of Proposition 1}

\section{A.2.1 Item (i)}

When regime 1 is permanent, the transversality condition implies that:

$$
C_{0}^{1}=\frac{\rho-\chi(1-\gamma)}{\gamma h}\left(H_{0}+\frac{h\left(p^{x} R-s\right)}{\chi}\right)
$$

Thus, existence requires $\rho>\chi(1-\gamma)$. More generally, relative size of $\chi$ and $\rho$ is crucial for the nature of potential solutions. First assume that $\rho>\chi$. Since, the stock of human capital is:

$$
H^{1}(t)=\frac{\gamma h C_{0}^{1}}{\rho-\chi(1-\gamma)} e^{\frac{(\chi-\rho) t}{\gamma}}-\frac{h\left(p^{x} R-s\right)}{\chi}
$$

it follows that $H_{\infty}^{1}=-\frac{h\left(p^{x} R-s\right)}{\chi}<0$, which is impossible. Thus, the system reaches the frontier $E^{1}=0$ in finite time. Next, consider the alternative, $\chi(1-\gamma)<\rho<\chi(\rho=\chi$ is a knife-edge situation). In this case, both consumption and human capital are varying at the constant rate $(\chi-\rho) / \gamma$. We disregard this case: this is either not compatible with the resource constraint or, if resource imports are allowed, it implies that $X^{1} \rightarrow-\infty$, which is not a reasonable feature of the model.

\section{A.2.2 Item (ii)}

The optimality condition 16 for the stopping time $T$ implies:

$$
C_{0}^{1}=(h \pi)^{-\frac{1}{\gamma}} e^{-\frac{(\chi-\rho) T}{\gamma}} .
$$


Substituting in (5), we obtain:

$$
\begin{aligned}
& C^{1}(t)=(h \pi)^{-\frac{1}{\gamma}} e^{\frac{1}{\gamma}(\chi-\rho)(t-T)} \\
& H^{1}(t)=\varphi(T) e^{\chi t}+\frac{\gamma h(h \pi)^{-\frac{1}{\gamma}}}{\rho-\chi(1-\gamma)} e^{\frac{(\chi-\rho)(t-T)}{\gamma}}-\frac{h\left(p^{x} R-s\right)}{\chi}
\end{aligned}
$$

where $\varphi(T) \equiv\left(H_{0}+\frac{h\left(p^{x} R-s\right)}{\chi}-\frac{\gamma h(h \pi)^{-\frac{1}{\gamma}} e^{-\frac{(\chi-\rho) T}{\gamma}}}{\rho-\chi(1-\gamma)}\right)$. The optimal stopping condition (15) can be rewritten as:

$$
\frac{\gamma(h \pi)^{-\frac{1-\gamma}{\gamma}}}{1-\gamma}+h \pi\left(p^{x} R-s\right)+\chi \pi H^{1}(T)=\rho \pi H^{1}(T)
$$

where the LHS is the marginal benefit of waiting, while the RHS is the marginal cost of waiting. Since $\frac{\gamma(h \pi)^{-\frac{1-\gamma}{\gamma}}}{1-\gamma}+h \pi\left(p^{x} R-s\right)>0, \chi \geq \rho$ implies that LHS $>$ RHS for each level of human capital.

When $\chi<\rho$, the RHS increases faster than the LHS. Then, the optimal end-point $H^{1}(T)=H_{T}$ is:

$$
H_{T}=\frac{h}{\rho-\chi}\left(\frac{\gamma(h \pi)^{-\frac{1}{\gamma}}}{1-\gamma}+p^{x} R-s\right)>0
$$

The second order condition (SOC) for the optimal stopping problem is satisfied iff $(\chi-\rho) \dot{H}^{1}(T)<$ 0 , which requires $\dot{H}^{1}(T)>0$. From the continuity of the state variable, we have:

$$
H_{T}=\varphi(T) e^{\chi T}+\frac{\gamma h(h \pi)^{-\frac{1}{\gamma}}}{\rho-\chi(1-\gamma)}-\frac{h\left(p^{x} R-s\right)}{\chi}
$$

Rearranging, we obtain:

$$
\varphi(T) e^{\chi T}=\frac{\rho h}{\rho-\chi}\left(\frac{p^{x} R-s}{\chi}+\frac{\gamma^{2}(h \pi)^{-\frac{1}{\gamma}}}{(1-\gamma)(\rho-\chi(1-\gamma))}\right)
$$

Let $F(T)$ be the LHS and $G>0$ the RHS. By the monotonicity of the path $\left\{H^{1}(t)\right\}_{t=0}^{T}$ (see the next item) and the SOC, $H_{0} \leq H_{T}$. Assume $H_{0}<H_{T}$. This is equivalent to $F(0)<G$. Moreover, $F(\infty)=-\infty$. The sign of the derivative of $F(T)$ :

$$
F^{\prime}(T)=e^{\chi T}\left(\chi H_{0}+h\left(p^{x} R-s\right)-h(h \pi)^{-\frac{1}{\gamma}} e^{-\frac{(\chi-\rho) T}{\gamma}}\right)
$$

For the existence of an optimal interior $T$, we need that $F^{\prime}(0)>0$, which is equivalent to:

$$
H_{0}>\underline{H}_{0}=\frac{h(h \pi)^{-\frac{1}{\gamma}}-h\left(p^{x} R-s\right)}{\chi} .
$$


and for the interval $\left(\underline{H}_{0}, H_{T}\right)$ to be non-empty, we must impose:

$$
p^{x} R-s+\frac{(h \pi)^{-\frac{1}{\gamma}}(\chi-\rho(1-\gamma))}{\rho(1-\gamma)}>0
$$

which is equivalent to the SOC.

We tackle existence by checking whether the optimality candidate exists for any $H_{0} \in\left[0, H_{T}\right]$. Substitute first $H_{0}=0$ in all the expressions above. Then, $F^{\prime}(0)>0$ simplifies to

$$
p^{x} R-s>(h \pi)^{-\frac{1}{\gamma}}
$$

and under this condition the SOC is satisfied.

Next, let $\tilde{T}$ be the time that maximizes $F(T)$. It satisfies:

$$
\tilde{T}=\frac{\gamma}{\rho-\chi} \ln \left(\frac{p^{x} R-s}{(h \pi)^{-\frac{1}{\gamma}}}\right)
$$

and for the existence of (at most two) $T^{*}>0$ that solve(s) (20), it must hold that $F(\tilde{T})>G$, or, equivalently:

$$
\frac{(\rho-\chi)^{2}}{\rho(\rho-\chi(1-\gamma))} e^{\frac{\gamma \chi}{\rho-\chi}}\left[\frac{p^{x} R-s}{(h \pi)^{-\frac{1}{\gamma}}}\right]^{2}>\frac{p^{x} R-s}{(h \pi)^{-\frac{1}{\gamma}}}+\frac{\gamma^{2} \chi}{(1-\gamma)(\rho-\chi(1-\gamma))}
$$

which is a simple polynomial of degree 2 in $\frac{p^{x} R-s}{(h \pi)^{-\frac{1}{\gamma}}}$. Now, under (23), this ratio is larger than 1 . So, a sufficient condition for $F(\tilde{T})>G$ is:

$$
e^{\frac{\gamma \chi}{\rho-\chi}}>\frac{\rho\left[(1-\gamma)(\rho-\chi(1-\gamma))+\gamma^{2} \chi\right]}{(1-\gamma)(\rho-\chi)^{2}}
$$

where both terms of the inequality above are greater than 1 . A quick inspection of the properties of the LHS and RHS of (25) as functions of parameter $\chi$, reveals that there exists a unique threshold $\underline{\chi} \in(0, \rho)$ such that $(25)$ holds iff $\underline{\chi}<\chi$.

The reasoning above is also valid for any $H_{0}>0$. Actually, the existence of a solution for the particular value $H_{0}=0$ implies that such a solution exists for any $H_{0}>0$. In general, the optimal stopping time can be expressed as a function $H_{0}: T^{*}=T\left(H_{0}\right)$ that satisfies, by differentiating (20):

$$
\frac{\partial T}{\partial H_{0}}=-\frac{1}{\chi \varphi\left(T\left(H_{0}\right)\right)+\varphi^{\prime}\left(T\left(H_{0}\right)\right)}
$$

Given that we want $\frac{\partial T}{\partial H_{0}}<0$ (uniqueness of the optimal trajectory), only the solution corresponding 
the increasing part of $F(T)$ is relevant, i.e. one has $F^{\prime}(T)>0$, which is equivalent to:

$$
p^{x} R-s>e^{\frac{(\rho-\chi) T}{\gamma}}(h \pi)^{-\frac{1}{\gamma}} .
$$

Comparative statics on $T^{*}$ that solves (20), given that this equation can be rewritten as $F(T, R, \pi)=$ $G(R, \pi)$. By the implicit function theorem, we have:

$$
\frac{\partial T}{\partial R}=\frac{\frac{\partial G}{\partial R}-\frac{\partial F}{\partial R}}{\frac{\partial F}{\partial T}} \text { and } \frac{\partial T}{\partial \pi}=\frac{\frac{\partial G}{\partial \pi}-\frac{\partial F}{\partial \pi}}{\frac{\partial F}{\partial T}}
$$

given that $\frac{\partial G}{\partial R}-\frac{\partial F}{\partial R}=\frac{h p^{x}(\rho-1)}{\chi}<0$ and $\frac{\partial G}{\partial \pi}-\frac{\partial F}{\partial \pi}=-\frac{h^{2}(h \pi)^{-\frac{1}{\gamma}}}{\rho-\chi(1-\gamma)}\left(\frac{\rho \gamma}{(\rho-\chi)(1-\gamma)}+e^{\frac{(\rho-\chi) T}{\gamma}}<0\right.$. Finally, since the solution satisfies $\frac{\partial F}{\partial T}>0$ (because we want $T^{\prime}\left(H_{0}\right)<0$ for all $H_{0} \geq 0$ ), we can conclude that $T^{*}$ is decreasing w.r.t. both $R$ and $\pi$.

\section{A.2.3 Monotonicity of trajectories}

The value function at any $H^{1}\left(t_{i}\right)=H_{i}$ taken on the optimal path is given by:

$$
V^{1}\left(H_{i}\right)=e^{-\rho \theta\left(H_{i}\right)}\left(\frac{\gamma(h \pi)^{-\frac{(1-\gamma)}{\gamma}}}{(1-\gamma)(\rho-\chi(1-\gamma))}\left[e^{\frac{(\rho-\chi(1-\gamma))}{\gamma} \theta\left(H_{i}\right)}-1\right]+\pi H_{T}\right)
$$

with $\theta\left(H_{i}\right)=T\left(H_{i}\right)-t_{i}$, the optimal time-to-go before stopping, which doesn't depend on $t_{i}$.

If there exists a non monotone optimal trajectory, it must be true that $H$ is first decreasing and then increasing. This implies that there exists $\left(t_{1}, t_{2}\right)$, with $t_{1}<t_{2}$, such that: $H^{1}\left(t_{1}\right)=H^{1}\left(t_{2}\right)$. Thus, we have $\theta\left(H_{1}\right)=\theta\left(H_{2}\right)$. The time that elapses between $t_{1}$ and $T\left(H_{1}\right)$ must be the same as the one between $t_{2}$ and $T\left(H_{2}\right)$. This yields a contradiction because the optimal trajectory is uniquely defined ( $H_{T}$ is invariant) and (initial) consumptions at $t_{1}$ and $t_{2}$ necessarily differ.

Finally note that the solution with positive education and a revolution in finite time yields the following present value to the elite:

$$
V^{1}\left(H_{0}\right)=e^{-\rho T\left(H_{0}\right)}\left(\frac{\gamma(h \pi)^{-\frac{(1-\gamma)}{\gamma}}}{(1-\gamma)(\rho-\chi(1-\gamma))}\left(e^{\frac{(\rho-\chi(1-\gamma))}{\gamma} T\left(H_{0}\right)}-1\right)+\pi H_{T}\right)
$$

This completes the proof of Proposition 1. 


\section{A.3 Proof of Proposition 2}

\section{A.3.1 Item (i)}

If regime 2 is permanent, then from the transversality condition $L=0$, and the solution reduces to (using the superscript 2):

$$
\begin{aligned}
& H^{2}(t)=H_{0} e^{-\delta t} \\
& C^{2}(t)=p^{x} R-s+\Omega H^{2}(t) \\
& \lambda^{2}(t)=-e^{(\rho+\delta) t} \int_{0}^{t} \Omega C(u)^{-\gamma} e^{-(\rho+\delta) u} d u(<0) .
\end{aligned}
$$

The value function is given by:

$$
V^{2}\left(H_{0}\right)=\int_{0}^{\infty} \frac{1}{1-\gamma}\left(p^{x} R-s+\Omega H_{0} e^{-\delta t}\right)^{1-\gamma} e^{-\rho t} d t
$$

\section{A.3.2 Item (ii)}

Consider a trajectory $\left(\left\{H^{1}\right\},\left\{C^{1}\right\}\right)$ that reaches the locus $E=0$ at date $t_{1}$ for some stock $H^{1}\left(t_{1}\right)=$ $\tilde{H}$ and consumption $C^{1}\left(t_{1}\right)=\tilde{C}$. From the dynamical system, both $H^{1}$ and $C^{1}$ are all decreasing w.r.t. time. The approach is to consider a solution with permanent $E=0$ as a limit case of the solution with a regime change from $E>0$ to $E=0$. Let's work with the general solution obtained by combining regimes 1 and 2 . For the time being, let $t_{1}$ be given. Recall that the general solution in each regime is:

$$
\begin{aligned}
& C^{1}(t)=C_{0} e^{\frac{(\chi-\rho) t}{\gamma}} \\
& H^{1}(t)=\left(H_{0}+\frac{h\left(p^{x} R-s\right)}{\chi}-\frac{\gamma h C_{0}}{\rho-\chi(1-\gamma)}\right) e^{\chi t}+\frac{\gamma h C_{0}}{\rho-\chi(1-\gamma)} e^{\frac{(\chi-\rho) t}{\gamma}}-\frac{h\left(p^{x} R-s\right)}{\chi}
\end{aligned}
$$

and,

$$
\begin{aligned}
& H^{2}(t)=\tilde{H} e^{-\delta\left(t-t_{1}\right)} \\
& C^{2}(t)=p^{x} R-s+\Omega H^{2}(t)
\end{aligned}
$$

From the continuity of consumption at $t_{1}$, we obtain: $C_{0}=\left(p^{x} R-s+\Omega \tilde{H}\right) e^{-\frac{(\chi-\rho)}{\gamma} t_{1}}$ and $C^{1}(t)=\left(p^{x} R-s+\Omega \tilde{H}\right) e^{\frac{(\chi-\rho)\left(t-t_{1}\right)}{\gamma}}$. From the continuity of the state variable at $t_{1}, \tilde{H}$ can be expresses as a function of $t_{1}: \tilde{H}=\zeta\left(t_{1}\right)$ with:

$$
\zeta\left(t_{1}\right)=\frac{(\rho-\chi(1-\gamma))\left[\left(H_{0}+\frac{h\left(p^{x} R-s\right)}{\chi}-\frac{\gamma h\left(p^{x} R-s\right)}{\rho-\chi(1-\gamma)} e^{-\frac{\chi-\rho}{\gamma} t_{1}}\right) e^{\chi t_{1}}-\frac{h(\rho-\chi)\left(p^{x} R-s\right)}{\chi(\rho-\chi(1-\gamma))}\right]}{\rho-\chi(1-\gamma)+\gamma \Omega h\left(e^{\frac{(\rho-\chi(1-\gamma))}{\gamma} t_{1}}-1\right)}
$$


So the value corresponding to this trajectory can be written as:

$$
\begin{aligned}
V\left(t_{1}\right)= & \frac{1}{1-\gamma}\left[\int_{0}^{t_{1}}\left(p^{x} R-s+\Omega \zeta\left(t_{1}\right)\right)^{1-\gamma} e^{\frac{(1-\gamma)(\chi-\rho)}{\gamma}\left(t-t_{1}\right)} e^{-\rho t} d t+\right. \\
& \left.+\int_{t_{1}}^{\infty}\left(p^{x} R-s+\Omega \zeta\left(t_{1}\right) e^{-\delta\left(t-t_{1}\right)}\right)^{1-\gamma} e^{-\rho t} d t\right]
\end{aligned}
$$

Taking the derivative w.r.t $t_{1}$ yields:

$$
\begin{aligned}
\frac{\partial V}{\partial t_{1}}= & \frac{1}{1-\gamma}\left(p^{x} R-s+\Omega \zeta\left(t_{1}\right)\right)^{1-\gamma} e^{-\rho t_{1}}+ \\
& +\frac{1}{1-\gamma} \int_{0}^{t_{1}} e^{-\frac{(\rho-\chi(1-\gamma)}{\gamma} t} e^{\frac{(1-\gamma)(\rho-\chi)}{\gamma} t_{1}}\left(p^{x} R-s+\Omega \zeta\left(t_{1}\right)\right)^{-\gamma}\left[(1-\gamma) \Omega \zeta^{\prime}\left(t_{1}\right)+\right. \\
& \left.+\frac{(1-\gamma)(\rho-\chi)}{\gamma}\left(p^{x} R-s+\Omega \zeta\left(t_{1}\right)\right)\right]- \\
& +\frac{1}{1-\gamma}\left(p^{x} R-s+\Omega \zeta\left(t_{1}\right)\right)^{1-\gamma} e^{-\rho t_{1}}+ \\
& +\int_{t_{1}}^{\infty} \Omega\left(\zeta^{\prime}\left(t_{1}\right)+\delta \zeta\left(t_{1}\right)\right) e^{-\delta\left(t-t_{1}\right)}\left(p^{x} R-s+\Omega \zeta\left(t_{1}\right) e^{-\delta\left(t-t_{1}\right)}\right)^{-\gamma} e^{-\rho t} d t
\end{aligned}
$$

Taking the limit when $t_{1} \rightarrow 0$, we obtain:

$$
\lim _{t_{1} \rightarrow 0} \frac{\partial V}{\partial t_{1}}=\int_{0}^{\infty} \Omega\left(\zeta^{\prime}(0)+\delta \zeta(0)\right)\left(p^{x} R-s+\Omega \zeta\left(t_{1}\right) e^{-\delta t}\right)^{-\gamma} e^{-(\delta+\rho) t} d t
$$

The sign of the limit is determined by the sign of $\zeta^{\prime}(0)+\delta \zeta(0)$. Direct computations yield: $\zeta(0)=H_{0}$ and the derivative of $\zeta\left(t_{1}\right)$ evaluated at $t_{1}=0$ is given by: $\zeta^{\prime}(0)=-\delta H_{0}$. Thus, $\zeta^{\prime}(0)+\delta \zeta(0)=0$. Applying multi-stage optimal control theory (interpreting the change from $E>0$ to $E=0$ as a regime switching problem), a necessary condition for an immediate switch $t_{1}=0$ is $\lim _{t_{1} \rightarrow 0} \frac{\partial V}{\partial t_{1}} \leq 0$ (see Amit [7], Theorem 1). Thus trajectories of the 1-2 type are always dominated by the ones associated with permanent $E=0$.

The last possibility is a regime change from 2 to 1 . Suppose the economy starts in regime $E=0$ and enters the region with positive education at $t_{1}<\infty$. Two options emerge. First, the economy stays in region 1 until the institutional change. This would imply the crossing of the locus $\dot{H}=0$ in finite time. Yet, this is excluded since the trajectory $\left\{H^{1}(t)\right\}$ must be monotonous (see Appendix A.2). Second, the economy stays for a while in regime 1 before going back in regime 2 . This is not optimal by the reasoning developed just above: the elite prefers instead to directly settle on the locus $E=0$.

This completes the proof of Proposition 2.

\section{A.4 Proof of Proposition 3}

At solution 1 (democratization), the index of inequalities is:

$$
I^{1}(t)=\frac{\left(s \chi-\phi h\left(p^{x} R-s\right)\right)}{\chi}(h \pi)^{\frac{1}{\gamma}} e^{\frac{(\rho-\chi)(t-T)}{\gamma}}+\phi \varphi(T)(h \pi)^{\frac{1}{\gamma}} e^{\frac{(\rho-\chi(1-\gamma)) t}{\gamma}} e^{\frac{(\chi-\rho) T}{\gamma}}+\frac{\phi \gamma h}{\rho-\chi(1-\gamma)}
$$


Take the derivative w.r.t time:

$$
\dot{I}^{1}(t)=\frac{(h \pi)^{\frac{1}{\gamma}}}{\gamma} e^{\frac{(\rho-\chi)(t-T)}{\gamma}}\left[(\rho-\chi)\left(s \chi-\phi h\left(p^{x} R-s\right)\right)+\phi\left(\rho-\chi(1-\gamma) \varphi(T) e^{\chi T}\right] .\right.
$$

The sign of the derivative is given by the sign of the term, denoted $\Psi$, in squared brackets. Evaluating $\Psi$ at $t=0$, gives:

$$
\Psi=(\rho-\chi) s+\phi(\rho-\chi(1-\gamma)) H_{0}+\gamma \phi h\left[p^{x} R-s-(h \pi)^{-\frac{1}{\gamma}} e^{\frac{(\rho-\chi) T}{\gamma}}\right]
$$

which is positive due to $(26)$. Thus $\dot{I}^{1}(t)>0$ for all $t \in[0, T]$.

At solution 2 (permanent dictatorship), the inequality index is:

$$
I^{2}(t)=\frac{s+\phi H^{2}(t)}{p^{x} R-s+\Omega H^{2}(t)}
$$

with derivative:

$$
\dot{I}^{2}(t)=\frac{p^{x} \dot{H}}{\left(p^{x} R-s+\Omega H^{2}(t)^{2}\right.}\left[\phi R-\frac{1-\alpha}{\alpha}\left(\frac{\alpha A}{p^{x}}\right)^{\frac{1}{1-\alpha}} s\right]
$$

Thus,

$$
R>\frac{(1-\alpha) s}{\phi \alpha}\left(\frac{\alpha A}{p^{x}}\right)^{\frac{1}{1-\alpha}}
$$

is sufficient to conclude that $\dot{I}^{2}(t)<0$ for all $t \in[0, \infty)$.

\section{A.5 Proof of Proposition 4}

The proof of the first item relies on a time consistency requirement for optimal trajectories. By contradiction, assume that $V^{1}\left(H_{T}\right)<V^{2}\left(H_{T}\right)$. Two case are possible.

Case 1: $V^{1}(0)<V^{2}(0)$. If the curves $V^{1}\left(H_{0}\right)$ and $V^{2}\left(H_{0}\right)$ intersect, then the number of intersections must be even. For instance, consider two intersections at $\hat{H}$ and $\tilde{H}$, with $0<\tilde{H}<$ $\hat{H}<H_{T}$. By construction, $V^{1}\left(H_{0}\right)>V^{2}\left(H_{0}\right)$ for all $H_{0} \in(\tilde{H}, \hat{H}) ; V^{1}\left(H_{0}\right)<V^{2}\left(H_{0}\right)$ for all $H_{0} \in[0, \tilde{H}) \cup\left(\hat{H}, H_{T}\right] ; V^{1}(\tilde{H})=V^{2}(\tilde{H}) ;$ and $V^{1}(\hat{H})=V^{2}(\hat{H})$.

At $H_{0}=\hat{H}$, there exist two optima, i.e. the elite are indifferent between following path 1 (with positive education) or path 2 (no education). If the economy settles on path 1 , then human capital increases (see Appendix A.2). Yet, by construction again, for any $H$ in $\left(\hat{H}, H_{T}\right], V^{1}(H)<V^{2}(H)$; i.e. the elite prefer path 2 to path 1 , implying that the solution considered is not time consistent. This yields a contradiction. If the elite chooses path 2, then human capital decreases monotonically (see Appendix A.3). Yet, $V^{1}(H)>V^{2}(H)$ for all $H \in(\tilde{H}, \hat{H})$; i.e. there is a (non-degenerate) interval of time during which the elite prefer regime 1. Again, this contradicts time consistency.

Case 2: $V^{1}(0)>V^{2}(0)$. Then, the number of intersections between $V^{1}\left(H_{0}\right)$ and $V^{2}\left(H_{0}\right)$ (if 
any) is odd. Assume a unique intersection at $\check{H}$. Then, $V^{1}\left(H_{0}\right)>V^{2}\left(H_{0}\right)$ for all $H_{0} \in[0, \check{H})$; $V^{1}\left(H_{0}\right)<V^{2}\left(H_{0}\right)$ for all $H_{0} \in\left(\check{H}, H_{T}\right]$; and $V^{1}(\check{H})=V^{2}(\check{H})$. At $H_{0}=\check{H}$, there is a multiplicity of optima. Either $E>0$ and $\dot{H}>0$. But then, $V^{1}(H)<V^{2}(H)$ for all $H \in\left(\breve{H}, H_{T}\right]$ and a contradiction emerges. Or, $E=0$ and $\dot{H}<0$ and, again, a contradiction emerges.

Proofs of the remaining items are left to the reader since they exactly follow the same line. In particular the reasoning of the second item is symmetric when one works with $V^{1}(0)>V^{2}(0)$. As for the third item, assuming that $V^{1}(0) \leq V^{2}(0)$ and $V^{1}\left(H_{T}\right) \geq V^{2}\left(H_{T}\right)$ (with one strict inequality), it's easy to show that there exists a unique intersection between the two value functions, for a critical initial stock of human capital $\bar{H}$ such that $V^{1}\left(H_{0}\right) \gtreqless V^{2}\left(H_{0}\right) \Leftrightarrow H_{0} \gtreqless \bar{H}$.

\section{A.6 Proof of Proposition 5}

For the sake of exposition, let $T(0)$ be denoted by $T$. Then, $V^{1}(0)>V^{2}(0)$ if and only if:

$$
e^{-\rho T}\left(\frac{\gamma(h \pi)^{-\frac{(1-\gamma)}{\gamma}}}{(1-\gamma)(\rho-\chi(1-\gamma))}\left[e^{\frac{(\rho-\chi(1-\gamma))}{\gamma} T}-1\right]+\pi H_{T}\right)>\frac{\left(p^{x} R-s\right)^{1-\gamma}}{\rho(1-\gamma)}
$$

which, by the definition of $H_{T}$ in (18) and by (20), yields:

$$
\frac{\left(p^{x} R-s\right)^{1-\gamma}}{\rho(1-\gamma)}<\frac{\gamma(h \pi)^{-\frac{(1-\gamma)}{\gamma}}}{\rho(1-\gamma)} e^{\frac{(\rho-\chi)(1-\gamma)}{\gamma} T}+\frac{h \pi\left(p^{x} R-s\right)}{\rho} e^{(\chi-\rho) T} .
$$

Denote the RHS of $(29)$ by $J(T)$. It follows that $J(0)=\frac{h \pi}{\rho}\left(\frac{\gamma}{1-\gamma}(h \pi)^{-\frac{1}{\gamma}}+p^{x} R-s\right)>0, \lim _{T \rightarrow \infty} J(T)=$ $\infty$ and:

$$
J^{\prime}(T)=\frac{h \pi(\rho-\chi)}{\rho} e^{(\chi-\rho) T}\left[(h \pi)^{-\frac{1}{\gamma}} e^{\frac{(\rho-\chi) T}{\gamma}}-\left(p^{x} R-s\right)\right] .
$$

We observe that $J^{\prime}(T) \leqq 0 \Leftrightarrow T \leqq \tilde{T}$, where $\tilde{T}$ has been defined in (24). Thus, imposing $J(\tilde{T})>$ $\frac{\left(p^{x} R-s\right)^{1-\gamma}}{\rho(1-\gamma)}$, which is equivalent to:

$$
p^{x} R-s>e^{\frac{\gamma}{1+\gamma}}(h \pi)^{-\frac{1}{\gamma}},
$$

is sufficient to conclude that $V^{1}(0)>V^{2}(0)$.

Moreover, whatever the regime, the value functions are strictly increasing in $H_{0}$, it's clear that a sufficient condition for having $V^{2}\left(H_{0}\right)>V^{1}\left(H_{0}\right)$ for all $H_{0} \in\left[0, H_{T}\right]$ is $V^{2}(0) \geq V^{1}\left(H_{T}\right)$, which is equivalent to:

$$
\frac{\left(p^{x} R-s\right)^{1-\gamma}}{\rho(1-\gamma)} \geq \pi H_{T} \Leftrightarrow \frac{\left(p^{x} R-s\right)^{1-\gamma}}{\rho(1-\gamma)} \geq \frac{\gamma(h \pi)^{-\frac{(1-\gamma)}{\gamma}}}{(\rho-\chi)(1-\gamma)}+\frac{\pi h\left(p^{x} R-s\right)}{\rho-\chi} .
$$

